\title{
Lapped Transforms in a JPEG 2000 Coder
}

\author{
Rafael G. de Oliveira and Ricardo L. de Queiroz
}

\begin{abstract}
Resumo-JPEG-2000 é o ultimo padrão de compressão de imagens e é baseado em decomposições espectrais hierárquicas via wavelets. Adaptamos o codificador de imagens JPEG-2000 para usar transformadas uniformes, trocando o estágio de wavelet por transformadas sobrepostas. $O$ tamanho dos blocos de codificação é escolhido de forma que contenha apenas coeficientes de uma sub-banda, que é codificada como se fossem coeficientes da wavelet. Os resultados indicaram um ganho de PSNR para várias imagens e corroboram resultados prévios que indicam um ganho típico das transformadas sobrepostas sobre wavelet em compressão de imagem.
\end{abstract}

Palavras-Chave-Transformadas sobrepostas, Wavelets, JPEG 2000, EBCOT

Abstract-JPEG-2000 is the latest image coding standard and is based on wavelet transforms and dyadic spectral decompositions. We have adapted the JPEG-2000 image coder for use with uniform transforms, by replacing the wavelet stage by lapped transforms. We set code-blocks that do not cross subband boundaries and encode the lapped transform coefficients directly as if they were wavelet ones. Results indicate a sizeable gain in PSNR for a number of images and corroborate previous results indicating typical gains of lapped transforms over wavelets in image compression.

Keywords-Lapped transform, Wavelets, JPEG 2000, EBCOT

\section{INTRODUCTION}

JPEG 2000 represents the state of art in image compression standards [1]. Even thought recent results have shown that the intra frame mode of H.264 might have an even better performance [2],[3], JPEG 2000 possesses some interesting features such as progressive compression (which is highly desirable in slow communication links), lossless and lossy compression, random code stream access, regions of interest, etc.

Many previous results have shown that some lapped transforms might haver superior coding gain in comparison to wavelets. For example, in [4], there are many comparisons among transforms such as the discrete cosine transform (DCT) [5], the 9/7-tap wavelet transform used in JPEG-2000 [1],[6],[7], and lapped transforms such as the lapped orthogonal transform (LOT) [8], the generalized LOT (GenLOT) [9], and the generalized lapped biorthogonal transforms (GLBT) [10]. The comparisons were carried for JPEG [11] and SPIHT [12] coders. Since early development on lapped transforms [13],[8], they have been compared to the DCT. In [14] the DCT was compared directly to wavelet transforms in the context of a JPEG coder [11], hence, one could indirectly infer the comparison between lapped transforms and wavelets. Since then, lapped transforms and coders evolved and, in [15], the

The authors are with the Departamento de Engenharia Elétrica, Universidade de Brasília, Brasília-DF, Brasil, E-mails: rafael@image.unb.br, queiroz@ieee.org.
SPIHT coder [12] was adapted to lapped transforms as well. Results in [4] point to a small but important improvement achieved by using lapped transforms for all codecs tested.

The focus of this work is to replace the wavelet transform used in JPEG 2000 by lapped transforms and to compare performances. In essence, we extend the above mentioned comparative works to encompass the JPEG-2000 coder as well. Only gray scale images are considered here, even though the coders are transparently applicable to color images as well.

\section{REPLACING WAVELETS BY LAPPED TRANSFORMS IN THE JPEG 2000 FRAMEWORK}

JPEG 2000 is based on the embedded block coding with optimal truncation (EBCOT) framework. The coefficients of each subband are divided into blocks. Each block is independently encoded, bitplane by bitplane, generating embedded streams in the process, which are concatenated. These embedded streams are truncated using an optimization algorithm in order to minimize $D+\lambda R$. The global distortion is calculated from the contribution of each independent code block:

$$
D=\sum_{i} D_{i}
$$

where the distortion of each code-block can be calculated as

$$
D_{i}=G_{b_{i}} \sum_{j}\left(\widehat{y}_{i}[j]-y_{i}[j]\right)^{2},
$$

and where $G_{b_{i}}$ depends on the filter used to generate the subband that the block belongs and $y_{i}[j]$ is the $j$-th coefficient of the $i$-th code block. In order to make the coder independent of the transform used, $G_{b_{i}}$ was made equal for all subbands. That may cause some small loss in the performance when using non orthogonal transformations, like the wavelet used in JPEG-2000 or the GLBT.

In order to use EBCOT to efficiently encode the coefficients, the subbands are encoded separately. For that to work, regardless of whether transform is uniform or hierarchical, code-blocks should not cross the subband boundaries. In other words, each code-block only contains coefficients of one subband. It is preferrable to define the code-blocks as a subband such that the entire subband belongs to one codeblock. Examples of code-block partitions are shown in Fig. 1 for the wavelet scheme and in Fig. 2. Note that JPEG2000's desirable features, such as regions of interest, quality progression, etc., are maintained regardless of the transform used.

The rate distortion curves for the popular $512 \times 512$-pixel image Barbara are shown in Fig. 3, where the typical PSNR (in $\mathrm{dB}$ ) and bit-rate (in bits per pixel, or bpp) parameters were used. In the tests, the code-block size was $64 \times 64$. Since 


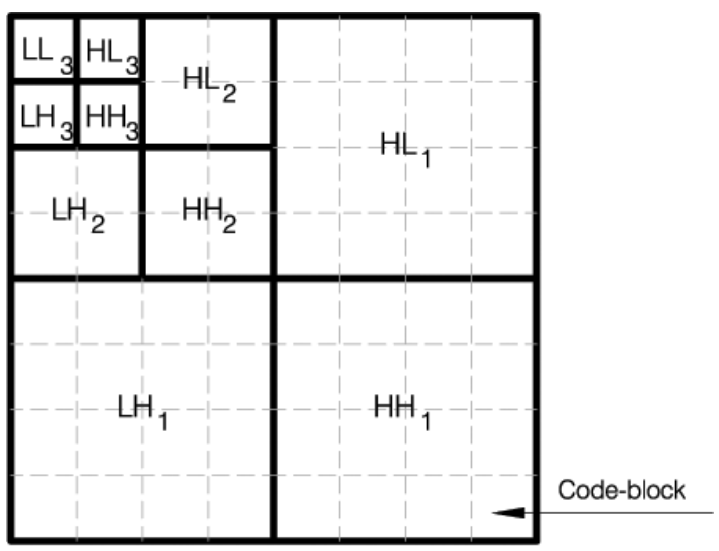

Fig. 1. Original codeblock and subband partition of coefficents for a threelevel wavelet decomposition.

\begin{tabular}{|l|l|l|l|}
\hline $\mathrm{S}_{0,0}$ & $\mathrm{~S}_{0,1}$ & $\mathrm{~S}_{0,2}$ & $\mathrm{~S}_{0,3}$ \\
\hline $\mathrm{S}_{1,0}$ & $\mathrm{~S}_{1,1}$ & $\mathrm{~S}_{1,2}$ & $\mathrm{~S}_{1,3}$ \\
\hline $\mathrm{S}_{2,0}$ & $\mathrm{~S}_{2,1}$ & $\mathrm{~S}_{2,2}$ & $\mathrm{~S}_{2,3}$ \\
\hline $\mathrm{S}_{3,0}$ & $\mathrm{~S}_{3,1}$ & $\mathrm{~S}_{3,2}$ & $\mathrm{~S}_{3,3}$ \\
\hline
\end{tabular}

Fig. 2. Codeblock partitioning for a uniform transform, where each codeblock contains one subband, $S_{i, j}$.

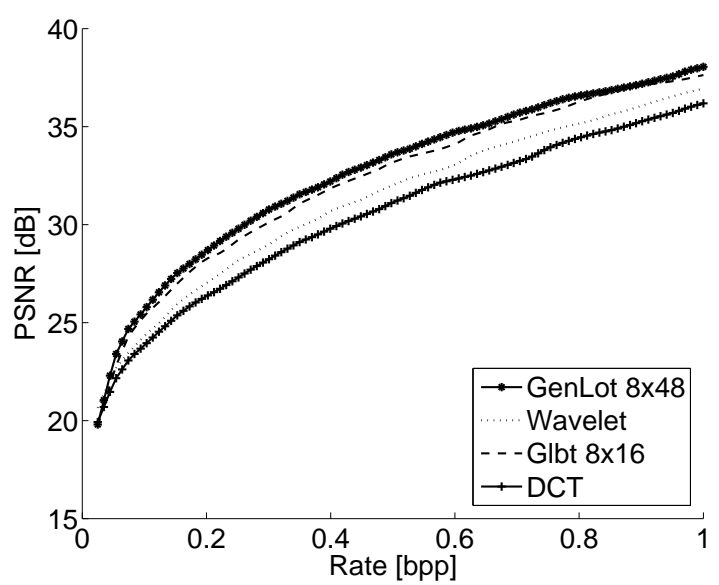

Fig. 3. PSNR curves for image Barbara and different transforms. Rate is given in bits per pixel (bpp). it is difficult to compare the different curves in Fig. 3, we used the standard 9/7-tap wavelet transform as a reference and plotted the differential PSNR relative to it. The comparative results for image Barbara in Fig. 3 are shown again in Fig. 4. The flat line (zero level) represents the performance of the wavelet and each curve is compared differentially. The results for three other popular images, Lena, Baboon and Goldhill, of the same dimensions $(512 \times 512$ pixels $)$ are shown in Figs. 5, 6, and 7 , respectively. The transforms in our comparison are the 8x8 DCT, the 8x48 GenLot, the 8x16 GLBT and the 9/7-tap wavelet, five level decomposition. The most impressive result is presented in Fig. 4, where the GenLot has its best results, about $1.8 \mathrm{~dB}$ above the wavelet curves. As expected, because of its elegant simplicity, the DCT had the worst performance.

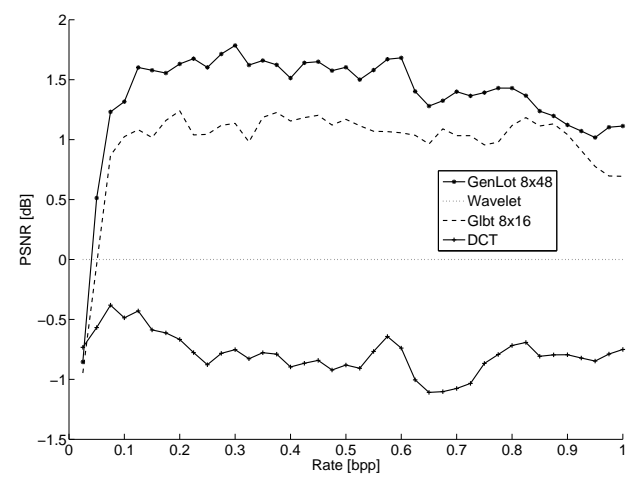

Fig. 4. Differential PSNR curves for image Barbara relative to the performance of the 9/7-tap wavelet.

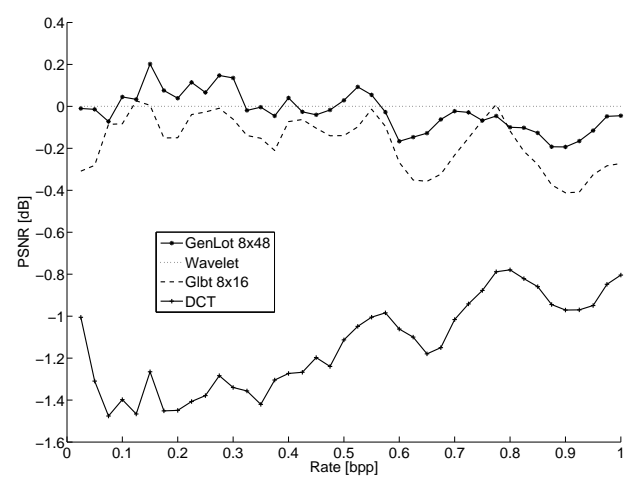

Fig. 5. Differential PSNR curves for image Lena relative to the performance of the 9/7-tap wavelet.

The details of the compressed image Barbara at 0.3 bpp are shown in Fig. 8 for different transforms.

\section{CONCLUSIONS}

This short paper introduces the use of lapped transforms in a JPEG-2000 coder and reports its performance. The results point to the superior performance of lapped transforms such as the GenLOT compared to the 9/7-tap wavelet transform traditionally used with JPEG 2000 coders. For images like Lena, the GenLOT is superior in some rates and worse for 


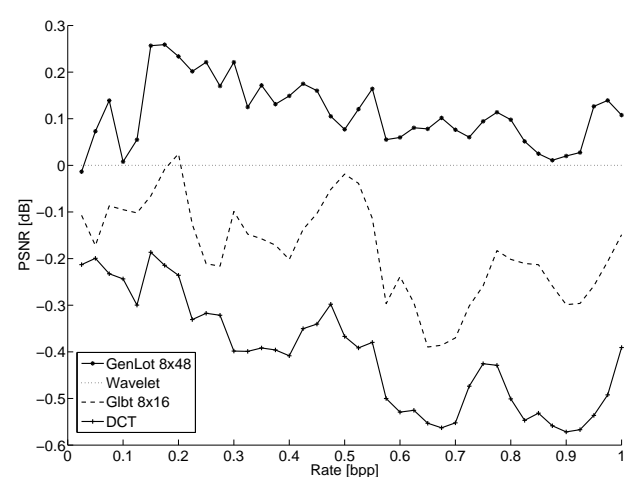

Fig. 6. Differential PSNR curves for image Baboon relative to the performance of the 9/7-tap wavelet.

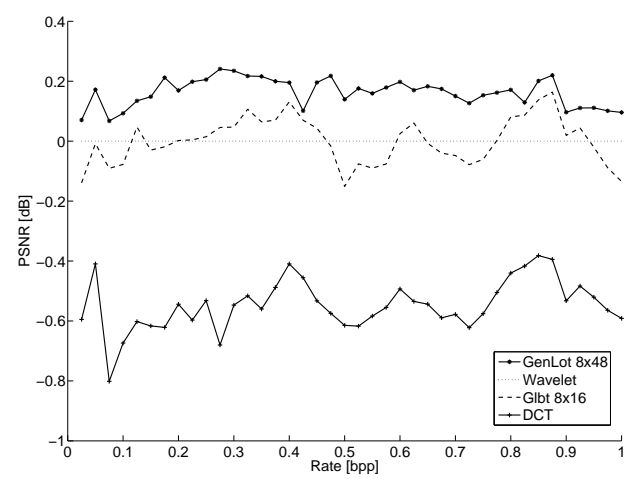

Fig. 7. Differential PSNR curves for image Goldhill relative to the performance of the 9/7-tap wavelet.

others. For other images the GenLOT consistently outperforms the wavelet decomposition. Actually, for image Barbara, gains are in the order of $1.5 \mathrm{~dB}$, which is a staggering margin. This result is one more evidence of the competitive performance of uniform lapped transforms in image compression.

\section{REFERENCES}

[1] D. S. Taubman and M. W. Marcellin, JPEG2000: Image Compression Fundamentals, Standards, and Practice, Kluwer Academic, 2002.

[2] D. Marpe, V. George, and T. Wiegand, "Performance comparison of intra-only H.264/AVC HP and JPEG2000 for a set of monochrome ISO/IEC test images," Contribution JVT ISO/IEC MPEG and ITU-T VCEG, JVT M-014, Oct. 2004.

[3] D. Marpe, V. George, H. L. Cycon, and K. U. Barthel, "Performance evaluation of Motion-JPEG2000 in comparison with H.264/AVC operated in pure intra coding mode," Proc. SPIE, Vol. 5266, pp. 129-137, Feb. 2004.

[4] R. L. de Queiroz and T. D. Tran, Lapped Transforms for Image Compression, Chap. 5 in The Handbook on Transforms and Data Compression, edited by K. R. Rao and P. Yip, CRC Press, 2001.

[5] K. R. Rao and P. Yip, Discrete Cosine Transform: Algorithms, Advantages, and Applications, San Diego, CA : Academic Press, 1990.

[6] M. Vetterli and J. Kovacevic, Wavelets and Subband Coding, Englewood Cliffs, NJ: Prentice Hall, 1995.

[7] G. Strang and T. Nguyen, Wavelets and Filter Banks, Wellesley, MA: Wellesley-Cambridge, 1996.

[8] H. S. Malvar and D. H. Staelin, "The LOT: transform coding without blocking effects," IEEE Trans. Acoust., Speech, Signal Processing, ASSP-37, pp. 553-559, Apr. 1989.

[9] R. L. de Queiroz, T. Q. Nguyen, and K. R. Rao, "GenLOT: generalized linear-phase lapped orthogonal transforms," IEEE Trans. on Signal Processing, Vol. 44, pp. 497-507, Apr. 1996.
[10] T. D. Tran, R. L. de Queiroz, and T. Q. Nguyen, "Linear phase perfect reconstruction filter bank: lattice structure, design, and application in image coding," IEEE Trans. on Signal Processing, Vol. 44, Jan. 2000.

[11] W. B. Pennebaker and J. L. Mitchell, JPEG: Still Image Compression Standard," New York, NY: Van Nostrand Reinhold, 1993.

[12] A. Said and W. A. Pearlman, "A new fast and efficient image codec based on set partitioning in hierarchical trees," IEEE Trans on Circuits Syst. Video Tech., vol. 6, pp. 243-250, June 1996.

[13] H. S. Malvar, Signal Processing with Lapped Transforms. Norwood, MA: Artech House, 1992.

[14] R. de Queiroz, C. Choi, Y. Huh, and K. R. Rao, “ Wavelet transforms in a JPEG-like image coder," IEEE Trans. on Circuits and Systems for Video Technology, Vol. 7, pp. 419-424, April, 1997.

[15] T. D. Tran and T. Q. Nguyen, "A progressive transmission image coder using linear phase uniform filter banks as block transforms," IEEE Trans. on Image Processing, to appear. 
XXV SIMPÓSIO BRASILEIRO DE TELECOMUNICAÇÕES - SBrT 2007, 03-06 DE SETEMBRO DE 2007, RECIFE, PE

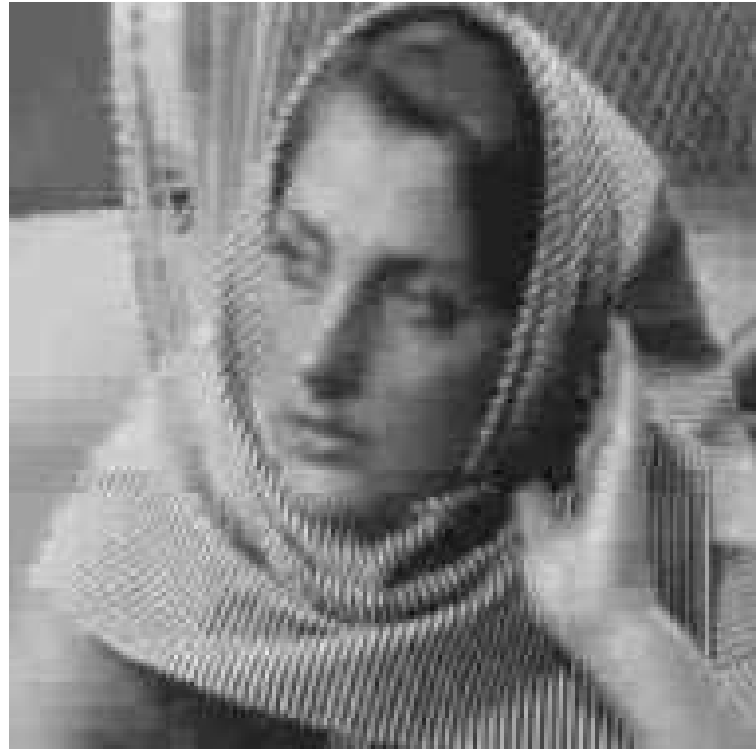

(a)

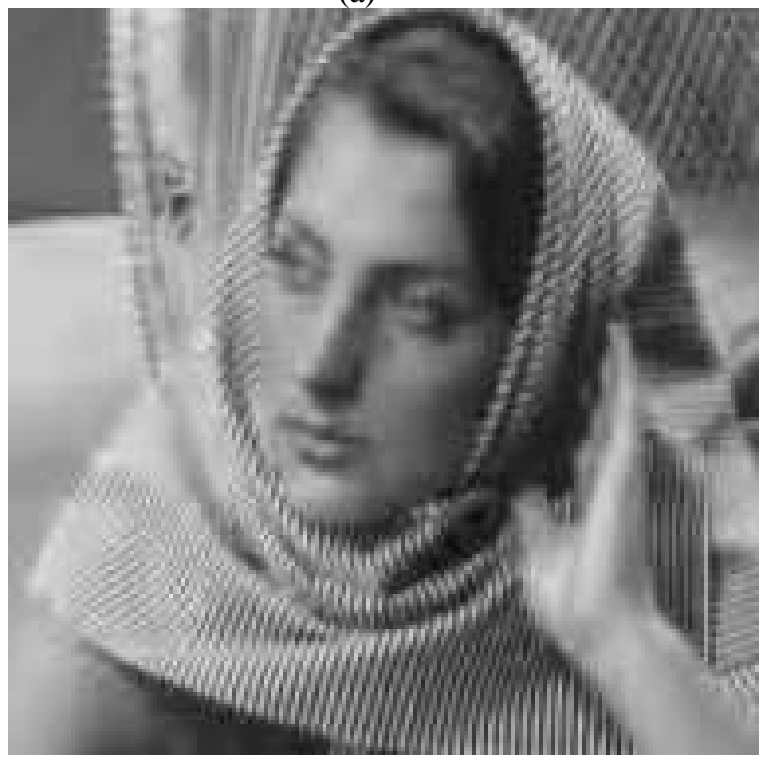

(c)

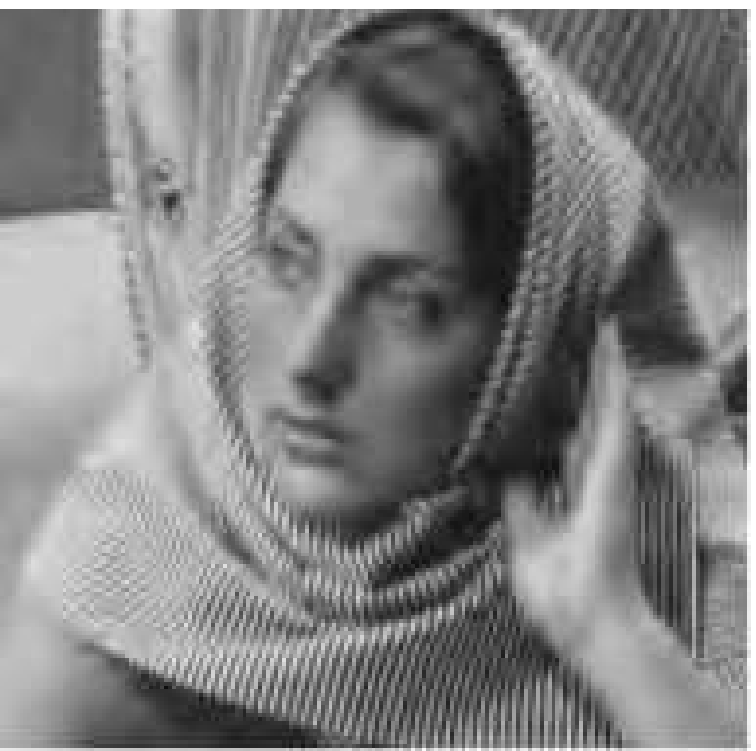

(b)

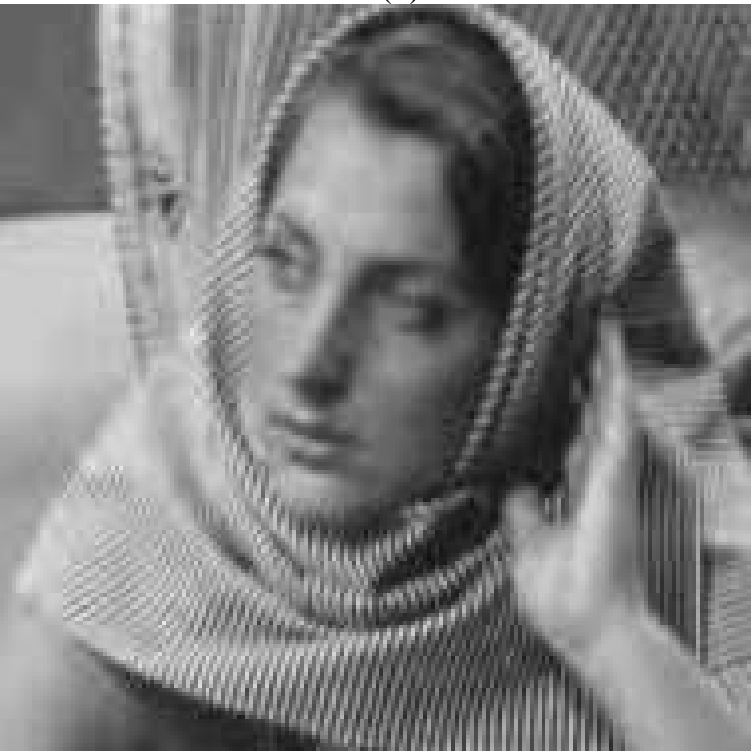

(d)

Fig. 8. Detail of image Barbara compressed at 0.3 bits/pel. (a) DCT, (b) wavelets, (c) $8 \times 16$ GLBT, (d) $8 \times 48$ GenLOT. 